\begin{tabular}{|c|l|}
\hline Title & Autochthonous bioaugmentation and its possible application to oil spills \\
\hline Author(s) & Hosokawa, Reia; Nagai, Motonori; Morikawa, Masaaki; Okuyama, Hidetoshi \\
\hline Citation & $\begin{array}{l}\text { World Journal of Microbiology and Biotechnology, 25(9), 1519-1528 } \\
\text { https://doi.org/10.1007/s11274-009-0044-0 }\end{array}$ \\
\hline Issue Date & 2009-09 \\
\hline Doc URL & http://hdl.handle.net/2115/43823 \\
\hline Type & article (author version) \\
\hline File Information & wjmb1.pdf \\
\hline
\end{tabular}

Instructions for use 


\title{
Autochthonous bioaugmentation and its possible application to oil spills
}

\author{
Reia Hosokawa ${ }^{1}$, Motonori Nagai ${ }^{1}$, Masaaki Morikawa ${ }^{1,2}$, Hidetoshi Okuyama ${ }^{1,2} *$ \\ ${ }^{1}$ Course in Environmental Molecular Biology and Microbial Ecology, Division of Biosphere \\ Science, Graduate School of Environmental Science, Hokkaido University, Kita-ku, Sapporo \\ 060-0810, Japan \\ ${ }^{2}$ Laboratory of Environmental Molecular Biology, Faculty of Environmental Earth Science, \\ Hokkaido University, Kita ku, Sapporo 060-0810, Japan
}

*Corresponding author. Hidetoshi Okuyama; Laboratory of Environmental Molecular Biology,

Faculty of Environmental Earth Science, Hokkaido University, Kita-ku, Sapporo 060-0810, Japan;

E-mail address,: hoku@ees.hokudai.ac.jp; Tel, +81-11-706-4523; Fax, +81-11-706-2347. 
Abstract Bioaugmentation (BA) for oil spills is a much more promising technique than is biostimulation (BS). However, the effectiveness of BA is variable, because the survival and the xenobiotic-degrading ability of introduced microorganisms are highly dependent on environmental conditions. As an alternative, autochthonous bioaugmentation (ABA) is proposed to overcome these difficulties. The ABA method is like a ready-made BA technology. In ABA, microorganisms indigenous to the contaminated site or predicted contamination site that are well-characterized and potentially capable of degrading oils are used, and these microorganisms should be enriched under conditions where BA will be conducted. It is possible to obtain information in advance on the chemical and physical characteristics of potential oil spill sites and of oils that might be spilled. The application of ABA in the coastal areas of Hokkaido Prefecture, Japan, is considered here, because Hokkaido is located south of Sakhalin Island, Russia, where development of oil fields is in progress. If oil spills in this region were well characterized in advance, ABA could be a feasible technology in the near future.

Keywords Autochthonous bioaugmentation • Bioremediation • Enrichment cultivation • Oil spill - Reinoculation $\cdot$ Sakhalin oil field 


\section{Introduction}

Oil spills seriously affect human activities and natural environments. In the past, mainly physical and chemical methods have been used to remove the contaminants. Biological methods such as bioremediation (BR) are considered to be relatively cost-effective and environmentally friendly. However, BR still faces many problems in its practical application.

There are two types of BR treatment: biostimulation (BS) and bioaugmentation (BA). Although BS is considered to be effective because indigenous bacteria are best adapted to the environment of the site that is being treated (Rahman et al. 2003), this is not always effective and may need a much longer time because of the scarcity of indigenous microbes capable of degrading hydrocarbons or high concentrations of the pollutants.

The BA treatment has been regarded as a promising technology, but is still in the experimental stage (Fantroussi and Agathos 2005 and references therein). This is because the survival and degrading ability of microbes introduced to a contaminated site are highly dependent on environmental conditions (Vogel 1996; Gentry et al. 2004a). Thus in many cases, potentially degrading strains isolated from site A are not necessarily applicable to site $\mathrm{B}$, and isolates including genetically engineered microorganisms that are efficient degraders of petroleum under laboratory conditions are not necessarily effective in situ (Sayler and Ripp 2000). Another difficulty is that it is 
not easy to get public acceptance for this technique.

In 1997, BA using a seed culture of petroleum-degrading bacteria, TerraZyme (Oppenheimer Biotechnology, Austin, Texas, USA) was attempted, on a trial basis, on the coast of Japan facing the Japan Sea after a heavy oil spill from the Russian tanker Nakhodka. It was shown that TerraZyme was able to enhance the biodegradation of oil on the shore (Tsutsumi et al. 2000). However, such exogenous microbial products have never been widely used in Japan. This is probably because the guidelines for BR, including BA using exogenous microorganisms, were not enacted in Japan until 2004. In addition, the wide-scale use of exogenous microorganisms imported from a foreign country might not have won public acceptance.

In early spring 2006 , the local news reported that more than 5,000 dead birds covered in oil had been found on the seashores of Hokkaido Prefecture, Japan (home page of Shari Town, Hokkaido; http://www.town.shari.hokkaido.jp/he2005/umidori/umidori2.html). Although the cause of this event was reported as mysterious (The Japan Times online, 18 March, 2006), it was easy for residents of Hokkaido to imagine that the birds became covered in oil in Sakhalin, Russia, where large-scale oil fields were being developed, and were then carried down to the Hokkaido coast facing the Sea of Okhotsk by the East Sakhalin Current. Unfortunately, no reports on this oil spill are available from governmental officials, but information on incidents such as oil spills from wells, pipelines, and ships, which are considered to be caused by the Sakhalin oil field development, can be seen at the 
home page (http://www.foejapan.org/en/) of FoE Japan, an international NGO.

Bioremediation is an indispensable technique for recovering lands including coastlines that have been contaminated with a thin and broadly-dispersed layer of crude oil or various petroleum products (Hosokawa et al. 2009). In this article, we look at various instances of the use of BA, mainly in petroleum-contaminated soil (sea sand), and we discuss the application of autochthonous BA as an alternative method.

\section{Trial and error in bioaugmentation}

The most typical outcome of BA is that the treatment is effective only during the early stages of the process. Therefore, BA treatment must sometimes be adjusted intermittently with the addition of more microorganisms. Ueno et al. (2007) compared BA using Pseudomonas aeruginosa WatG with BS in paddy soil that had been artificially contaminated with diesel oil. P. aeruginosa WatG was isolated from a water interceptor attached to an oil tank and is capable of degrading various types of petroleum products in liquid culture (Wongsa et al. 2004) and in soil (Ueno et al. 2006a). During the first two weeks, a higher rate of degradation of the diesel oil was observed using BA than was observed using BS, but after this time no difference in the rate of degradation was observed between the two treatments. A similar result was observed for BA using petroleum-degrading Thalassolituus 
oleivorans strain SLHC162b (McKew et al. 2007). When this strain was introduced to crude

oil-contaminated water, degradation of $n$-alkanes was observed only during the initial five days, and the extent of degradation was lower than that achieved by BS, where nitrogen, phosphorus and rhamnolipid (biosurfactant) were added. It was considered that the failure of BA using T. oleivorans might have been caused by using a bacterial species phylogenetically distant from bacteria indigenous to the site (McKew et al. 2007). According to Møller et al. (1995), a commercial microbial mixture designed for BA that was administered to diesel oil-contaminated soil showed no degradation of diesel oil but its application to the soil in large quantities repressed the degradation ability of indigenous microorganisms.

The proliferation of exogenous microorganisms administered to soil is affected by biotic and abiotic factors in soil environments. van Veen et al. (1997) indicated that abiotic factors in soil, such as clay minerals, water tension, organic carbon, inorganic nutrients, $\mathrm{pH}$, temperature and chemicals, will affect the survival and degradation activity of introduced microbes. Bacteria are known to become prey for indigenous predators such as protozoa (Bouchez et al. 2000). Gurijala and Alexander (1990) observed that some bacterial species introduced to soil persisted after an initial reduction in their cell numbers, but others were undetectable after three or fifteen days of incubation. A decrease in the number of protozoa and the suppression of the growth of protozoa led to an elimination or delay in the depletion of inoculated bacteria, suggesting that protozoan predation was 
the main factor in the fall in population of introduced bacteria.

Successful BA treatments depend on the use of inocula consisting of single microbial strains or microbial consortia that have been well adapted to the site to be decontaminated. Foreign microorganisms (those in inocula) are unable to avoid competition with indigenous bacteria, predators and various abiotic factors. Factors affecting proliferation of microorganisms used for BA include the chemical structure and concentration of pollutants, the availability of the contaminant to the microorganisms, the size and nature of the microbial population and the physical environment (Vogel and Walter 2001). Therefore, it will be more practical when using BA to use microorganisms isolated from the soil that is to be decontaminated. That is, it is best to use autochthonous microorganisms rather than allochthonous ones (see sections 5 and 6).

\section{Use of molecular techniques for bioaugmentation}

It is possible to monitor changes in the microbial community structure during BA and BS treatments in soil using molecular techniques. Changes in bacterial community structure during BS and BA treatments of paddy soil contaminated with diesel oil were monitored using polymerase chain reaction-denaturing gradient gel electrophoresis (PCR-DGGE) targeting 16S rRNA genes (Ueno et al. 2006b). The BA treatment using exogenous $P$. aeruginosa strain WatG was effective for only two 
weeks, which coincided with a decrease in the intensity of the DGGE band for strain WatG. It is interesting to note that this decrease in band intensity for strain WatG also coincided with an increase in the intensity of bands for some intrinsic bacteria that showed no diesel-degrading activity (Ueno et al. 2006b; Ueno et al. 2007).

Major et al. (2002) demonstrated that tetrachloroethene in soil was successfully dechlorinated to ethene by BA using a dechlorinating microcosm KB-1 enriched from groundwater. The microcosm contained strains phylogenetically close to Dehalococcoides ethanogenes. Throughout the test period, BA-treated groundwater samples were monitored by PCR targeting 16S rRNA gene sequences specific for Dehalococcoides. Using this technique, it appeared that the KB-1 consortium became predominant in the soil. The dominance of the consortium was accompanied by the degradation and dechlorination of tetrachloroethane.

The BA treatment could be accomplished successfully using genetically modified indigenous bacteria. Various genes encoding enzymes involved in the degradation of hydrocarbons have been cloned (van Beilen et al. 2001; van Homme et al. 2003). Recombinant bacteria, in which such genes are engineered, have been used for BA (Bathe et al. 2005; Nancharaiah et al. 2008). For example, Watanabe et al. (2002) genetically modified Comamonas sp. rN7, a component of activated sludge, with phc genes from Comamonas testosteroni $\mathrm{R} 5$ that encoded phenol hydroxylase and transcriptional regulators. This enhanced the phenol-oxygenating activity of Comamonas sp. rN7. 
The use of genetically engineered microorganisms for BA has great potential, although it faces greater difficulties in winning social acceptance. However, because the use of recombinants will most likely become more common in the future, it is necessary to collect data on the behaviour of recombinant strains in soils and their effects on ecology.

Schneiker et al. (2006) determined the whole sequence of Alcanivorax borkumensis SK-2, which is regarded as a ubiquitous marine hydrocarbon-degrading bacterium. The most distinctive feature of this bacterium is its ability to grow efficiently and almost exclusively on alkanes (van Beilen et al. 2004; Hara et al. 2003; Yakimov et al. 1998). This feature was clarified by characterization of the genome sequence of this bacterium, where a number of systems for the catabolism of hydrocarbons, such as clusters of genes encoding proteins involved in alkane degradation and candidate genes involved in biosurfactant production, are found (Schneiker et al. 2006). Alkanivorax strains grew predominantly in oil-contaminated and nutrient-supplemented seawater (Kasai et al. 2002). It is interesting to note that when the growth of Alkanivorax strains indigenous to a seawater competed with exogenous oil-degrading marine Alkanivorax venetianus strain T4 in crude oil-containing seawater supplemented with nitrogen and phosphorus nutrients, (1) indigenous Alkanivorax strains predominated in the cultures as ascertained by PCR-DGGE and fluorescence in situ hybridization, and (2) one Alkanivorax borukumensis strain (ST-Y1) isolated from the seawater used in cultivation exhibited higher ability to degrade Arabian crude oil than A. venetianus strain T4 did (Hara et al. 
2003). These results suggested that the use of isolated indigenous bacterial strains would be superior to that of exogenous strains even under liquid cultivation conditions that are analogous to those in situ in the seawater where samples were collected. Molecular techniques are useful for understanding the genetic background of oil-degrading bacteria with high capacity to degrade crude oils and generate desired recombinant strains, and also for investigating the microbial structures of sites to be cleaned up. It is necessary that such molecular information be linked to allow its use in practical BA under marine and terrestrial conditions.

Review papers by Sayler and Ripp (2000) and Cases and de Lorenzo (2005) summarize BA processes using genetically modified bacteria. The former describes the difficulty for genetically engineered bacteria applied to a natural environment to prevail against indigenous bacteria because of inherent stresses caused by the introduction of foreign genetic elements. In the latter, it is stated that bacterial strains such as Pseudomonas and Rhodococcus species, which are fast-growing and could be relatively easily enriched under artificial conditions, would predominantly not be present in natural environments, and therefore that genes for the wanted catalytic activities should be introduced to a microbial community (indigenous bacterial consortia) by means of promiscuous plasmids or other genetic elements.

\section{Problems in bioaugmentation}


It is noteworthy that commercially available microbial cultures for BA were not efficacious when compared with indigenous bacteria in soils (Møller et al. 1995) and even in liquid cultivation conditions (Dott et al. 1989). Several major difficulties are inherent in the practical use of traditional BA technology. First, soil environments are physically, chemically and biologically too complex as a matrix even for microorganisms with a high degradation potential to proliferate using petroleum as a carbon source, particularly when isolated from sites other than the ones being decontaminated. As described above, allochthonous (foreign) microorganisms added to soils tend to be effective only in the early stages of BA, during which time their high population can be maintained. However, such dominance of single strains is lost rapidly in soil. Second, allochthonous microorganisms are not necessarily the best strains to use for BA, even though many microorganisms have been isolated and described as efficient degraders. It is well known that most environmental bacterial strains are unculturable under laboratory conditions (see section 6). It is better to focus our attention for BA on strains that are unculturable in laboratories but culturable in the environment, where they are able to proliferate. Most bacterial isolates and consortia used for BA bioremediation of petroleum-contaminated sites are obtained by enrichment cultivation using liquid media that contain crude oil or some petroleum product or by common plating. However, isolates or consortia collected in such a way do not demonstrate their degradative ability in soils (Atagana et al. 2004). Ueno et al. 
(2007) detected at least ten bacterial strain bands in BS-treated and six in BA-treated soils using

PCR-DGGE targeting 16S rRNA genes. However, only one and two of these strains, respectively, could be isolated from BS and BA soils by a combination of common liquid cultivation and plating procedures. These results suggest that not all strains detected by PCR-DGGE can necessarily be isolated by plating and that most of these strains proliferate in soil but not on solid or in liquid media ex situ. This finding coincides with the finding that most soil bacteria are unculturable (Torsvik et al. 1990). Therefore, enrichment cultivation of petroleum-hydrocarbon-degraders in soils has the benefit of allowing the accumulation of microorganisms to be used for BA in contaminated soils. Third, it is generally difficult to gain public acceptance for using foreign and genetically engineered microorganisms, even for the bioremediation of petroleum-contaminated sites. However, such difficulties might be solved by using the more sophisticated ABA technology.

\section{Past and present autochthonous bioaugmentation}

Autochthonous bioaugmentation (ABA) is defined as a BA technology that uses microorganisms indigenous to the sites (soil, sand, and water) to be decontaminated (Ueno et al. 2007). Isolated single strains or enriched cultures, which can be obtained "before" or "after" the contamination of the target sites, are inoculated into the sites once the sites are contaminated. Enrichment of 
contaminant-degrading bacteria should be conducted under the same or very similar conditions to those where BA will be performed. According to Vogel and Walter (2001), BA can be divided into three classes: one type is the enrichment or isolation of microorganisms from the target site, their subsequent culturing and reinoculation; in the second type of BA, isolates or enrichments are not inoculated to the source of the original culture; and the third type is the use of constructed or force-mutated microorganisms. $\mathrm{ABA}$ has the same concept as the first type of $\mathrm{BA}$ defined by Vogel and Walter (2001) and this method has also been called "reinoculation" (Weber and Corseuil 1994). The ABA (reinoculation) technique exploits the advantages of BS, and the disadvantages of BS are counteracted by the use of BA treatment. ABA as defined in this study uses indigenous microbial consortia or isolates that are highly enriched and much better adapted to the historically or artificially contaminated environments (Hosokawa et al. 2009).

The term autochthonous bioaugmentation was originally proposed by Ueno et al. (2007). One bacterial species (isolate J identified as Rhodococcus erythropolis) was isolated from a diesel-contaminated soil microcosm (paddy soil) that had been biostimulated with Luria-Bertani (LB) medium (Table 1). This isolate degraded diesel oil that was present in the paddy soil supplemented with LB or mineral salts medium (MSM). The BA capacity of isolate $\mathrm{J}$ in the soil microcosms contaminated with diesel oil was much higher than that of $P$. aeruginosa strain WatG, which was used as a potential diesel oil-degrading microorganism. 
As described above, the ABA technique is not a new concept. However, only a limited number of reports have been published on $\mathrm{BA}$ conducted as $\mathrm{ABA}$ (reinoculation) compared with other types of BA treatments. This is probably because the practical benefits of this method (ABA) have not been recognized. Thompson et al. (2005) indicated that it was not practical to search for contaminant-degrading microorganisms to use in BA after the occurrence of an oil spill. Table 1 summarizes examples of BA treatments that are considered to use the ABA (reinoculation) method.

Otte et al. (1994) conducted ABA using microbially enriched soil as an inoculum. Pentachlorophenol (PCP) and polycyclic aromatic hydrocarbons (PAH) were degraded aerobically by microorganisms in the enriched soil. Degradation of PCP was $50 \%$ after $36 \mathrm{~h}$, while no mineralization was observed in uninoculated soil. The mineralization rate of phenanthrene and pyrene in inoculated soil was 30-fold and 81-fold, respectively, compared with that in uninoculated soil. Similarly, a petrochemical waste (Vecchioli et al. 1990), benzo[a]pyrene and carbazol (Grosser et al. 1991), and various oil products such as gasoline and diesel fuel (Belloso 2003a) present as contaminants in soils were efficiently degraded ex situ by indigenous soil bacteria in microcosms enriched from the contaminated soils. Weber and Corseuil (1994) used laboratory soil columns artificially contaminated with benzene, toluene and xylene to rapidly increase the populations of specific microorganisms. Reinoculation of the soils with these microorganisms enhanced the rate of degradation of the contaminants in the soil. 
Fungi are more useful than bacteria for ABA, because they generally have a good ability to immobilize toxic metals (Atagana 2004; Potin et al. 2004; D'Annibale et al. 2006). Sites polluted with recalcitrant organic compounds are often contaminated with heavy metals (D'Annibale et al. 2006). Filamentous fungi are more valuable than bacteria owing to their motility. They can reach and use contaminants in soils by growing hyphae (Garon et al. 2004).

There are some instances of successful ABA using fungi. D'Annibale et al. (2006) evaluated the effectiveness of BA using fungi autochthonous to soil that had been historically contaminated for more than 100 years. Soils contaminated by aromatic hydrocarbons, including chlorinated benzenes, anilines, thiophenes and PAH, and which concomitantly contained heavy metals, were not decontaminated using allochthonous fungi probably because of the complicated characteristics of the soils. However, autochthonous fungi, which were regarded as organisms that had become naturally enriched in the polluted site over a long period, showed a capacity to degrade high concentrations of contaminants and/or multiple contaminants in the soil.

The ABA method has been used in water treatment. Takeuchi et al. (2005) adopted ABA for remediating an aquifer. Aquifer material contaminated with methane, which was collected from an area near a gas field, was used as inoculum to decontaminate cis-dichloroethylene in the aquifer. The chemical oxygen demand and biochemical oxygen demand of wetlands contaminated with organic compounds were reduced by $69 \%$ and $70 \%$, respectively, after inoculating the site with wastewater 
(Belloso et al. 2003b).

Interestingly, Gentry et al. (2004a) compared the effectiveness of uncontaminated soil and soil contaminated with 2-, 3- and 4-chlorobenzoate as inoculum for the decontamination of chlorobenzoate-contaminated soil. Soils to be decontaminated and those used for inocula were collected from different sites but had similar contents of organic carbon, nitrogen, sand, silt and clay.

After BA treatment, much more contaminant was removed by chlorobenzoate-contaminated soil than by uncontaminated soil, suggesting that chlorobenzoate-degrading bacteria were activated and they had increased their population in the contaminated soil before being inoculated.

Blumenroth and Wagber-Döbler (1998) provided one unsuccessful example of reinoculation.

When a river sediment sample contaminated with various pollutants, including hydrocarbons and heavy metals, was inoculated to the autoclaved slurries of the original sediment, cell density in the culture increased. However, all inoculants died out when the inoculum was added to live sediment slurries. It was concluded that the use of indigenous isolates for bioremediation (reinoculation) did not provide any advantage in dynamic, highly competitive environments.

\section{Preparation for autochthonous augmentation at predicted contamination sites}

It is not hard to predict where oil spills may occur, although it is difficult to know when they will 
occur. Areas close to oil fields are threatened with many types of oil spill, such as eruption of oil wells and spills from storage tanks and pipelines. Coastlines along the routes followed by tankers face the risk of oil spillage from the tankers. We can accumulate information on the chemical and physical characteristics of soil and water from sites predicted to be at risk of oil contamination, and on the molecular characteristics of the crude oils and petroleum products that might be spilled.

We assessed the effectiveness of ABA along the coast of Hokkaido Prefecture, Japan. The island of Hokkaido is located to the south of Sakhalin Island, Russia, where a large-scale development of oil fields is in progress (Murakami 2002; Fig. 1). The coast of Hokkaido facing the Sea of Okhotsk and the Sea of Japan are at risk of oil contamination from the Sakhalin oil fields (Murakami 2002), because the East Sakhalin Current flows southward towards Hokkaido along the east coast of Sakhalin Island (Oshima et al. 2002) and the navigation of tankers through the Soya Strait (Fig. 1) is being considered. The Soya Strait, $42 \mathrm{~km}$ wide and $30-40 \mathrm{~m}$ deep, is subject to the risk of marine peril caused by stormy winds of $10 \mathrm{~m} / \mathrm{s}$ or greater (131 days per year) and frequent sea fogs during the spring and summer seasons (Saeki and Otsuka 2002). These risks have been recognized by the oil development company (Sakhalin Energy: http://www.sakhalinenergy.ru/en/aboutus.asp) and by the government of Japan, and various countermeasures against them are being planned by the Japanese Ministry of Land, Infrastructure, Transport and Tourism (http://www.mlit.go.jp/index_e.html). 
So far, no attention has been paid to oil spills originating from the Sakhalin oil fields from the point of view of using BR, despite Hokkaido having a severely cold climate, the Sea of Okhotsk being covered by sea ice in winter (Uto et al. 1995), and Shiretoko being on the UNESCO list of World Heritage Sites (http://whc.unesco.org/en/list/1193) and having good fishing zones in the vicinity. To reduce environmental damage in economically important places such as Shiretoko, special attention must be paid to conducting remediation treatments (Aota 2002) including BR.

We collected samples of sea sand at two sites, Shari Town and Abashiri City facing the Sea of Okhotsk and at Ishikari City facing the Sea of Japan (Fig. 1). The sea sands from Shari (located on the Shiretoko Peninsula) were contaminated artificially with $1 \%$ crude oil and incubated in the presence of NSM. About $30 \%$ of the crude oil was degraded after two weeks. PCR-DGGE analysis targeting 16S rRNA genes of the biostimulated soil showed several major bands, which were suspected to be those of crude oil-degrading bacteria. These included strains similar to Pseudomonas aeruginosa S2-77, Pseudomonas angulliseptica clone SE26, and Shewanella putrefaciens. These results suggest that seashore sands from this site have potential for use in ABA after appropriately enriching the crude-oil degrading consortia (Hosokawa et al. 2009).

Crude oil-degrading microbial consortia of sea sands collected on the seashores of Abashiri, Hokkaido, were enriched using liquid and sea sand-containing solid media supplemented with MSM and crude oil. When unsterilized sand from the same place was inoculated with two types of 
microbial consortia, degradation of crude oil was greater in the consortium prepared by cultivation in sand (consortium 2) than in that prepared by liquid cultivation (consortium 1). The extent of degradation of crude oil by consortium 1 was almost the same as that by BS. PCR-DGGE analysis targeting 16S rRNA genes of the bacterial consortia showed that consortium 2 included diverse faint DGGE bands suspected to be those derived from crude oil degraders. However, the BS consortium and consortium 1 included three very predominant bands, by which proliferation of some of the degraders found in consortium 2 were probably depressed. These results suggest that various types of bacteria are involved in the degradation of crude oil in sea sands and that proliferation of these bacteria might be hindered by the occurrence of extremely predominant strains. For a more practical application of $\mathrm{ABA}$, microbial sources should be acquired from the site to be decontaminated, and consortia or isolates should be prepared under the same cultivation conditions as those where BA will be conducted (Hosokawa et al. 2009). Only one and three strains were isolated from the consortia 1 and 2, respectively, derived from Abashiri sea sand (Nagai 2009), suggesting that most bacterial species detected as DGGE bands are not culturable on agar plates. The strain from the consortium 1 degraded approximately 50\% of the crude oil in a liquid MSM supplemented with $1 \%$ crude oil at $20^{\circ} \mathrm{C}$ after two weeks. Interestingly, however, no degradation of crude oil was observed in the MSM-containing sea sands (in sand microcosm). The strains isolated from the consortium 2 degraded crude oil under sand-containing cultivation conditions but not under liquid cultivation 
conditions (Nagai 2009). These results suggested that the proliferation of bacteria indigenous to sea sand is highly dependent on their environment. Sea sand samples from Ishikari (see Fig. 1) showed almost the same results; microorganisms enriched using sea sand-containing solid medium supplemented with crude oil and MSM degraded crude oil much more than those enriched in liquid MSM (Motonori Nagai, Reia Hososaka, and Hidetoshi Okuyama, unpublished result).

Although Gentry et al. (2004b) summarized various approaches for BA, which included (1) BA using cells encapsulated in a carrier such as alginate; (2) rhizosphere BA where the microbial inoculant is added to the site along with a plant; and (3) phytoaugmentation where the remediation genes are engineered directly into a plant for use in remediation without a microbial inoculant, neither ABA nor inoculation were discussed. The term "augmentation with indigenous microorganisms" for site remediation is used in the review by Fantroussi and Agathos (2005). However, this term also does not include the concept of ABA.

\section{Conclusions and perspectives}

The ABA method is like a ready-made technology for the decontamination of oil-polluted lands, coasts and waters and has a number of advantages: shorter treatment time, greater potential efficiency, lower impact on the environment, and relative ease in obtaining public support. 
As pointed out by Thompson et al. (2005), it is not practical to isolate single oil-degrading bacteria and to establish consortia enriched with oil-degrading bacteria once an oil spill has happened. To overcome such problems, prompt procedures for obtaining potential strains and consortia that can be used immediately after the occurrence of an oil spill must be developed.

However, it is possible to gain knowledge of the microbial community structure of the targeted soil and water before and after contaminating them artificially with oil, and also possible to isolate, in advance, potential autochthonous microorganisms and their consortia capable of degrading the sorts of oils that are likely to be spilled. Individual isolated strains and/or microbial consortia useful for ABA would be obtained more efficiently by the combined use of classical enrichment cultivation and molecular analyses under autochthonous conditions. The process for enriching oil-degrading microorganisms must be performed under conditions analogous to those where the BA will be conducted.

Detailed characterization of isolated microbes and consortia is necessary for their efficient use in ABA. Nutrients, oxygen supply and temperature are abiotic characteristics of an environment that need to be considered for optimal use of these microbes and consortia. Breeding of consortia would be useful for the development of ABA. The most appropriate method of storage and recovery from stock for the isolated individual strains and consortia must be established. A database needs to be established, containing all available information on individual strains and consortia, geological 
characteristics of soil and waters that are at risk of contamination, and technical knowledge. This preparation for ABA should be expected for every place in the world that is at risk of oil contamination.

\section{Acknowledgements}

Akio Ueno greatly contributed in the work on bioremediation conducted in our laboratory and provided critical feedback on this manuscript. The contribution by Jun Teragaki and Hanae Kondo is also appreciated. The authors also thank Dr. Y. Masuda of Shari Town Office, Hokkaido Prefecture, for his cooperation in sampling at Shiretoko and A. Kubo for her assistance in preparing the figure. This work was partly supported by Grant-in-Aid for Scientific Research ((C) no. 17510061) from the Ministry of Education, Science, Sports, and Culture of Japan and grants from Northern Advancement Center for Science \& Technology, the Sumitomo Foundation and Institute for Fermentation, Osaka (IFO). 


\section{References}

Aota M (2002) Sea ice and global environment (original title is in Japanese). In: Murakami T (ed)

Sakhalin offshore oil and gas development and environment protection, Hokkaido University

Press, Sapporo, pp. 141-160 (in Japanese)

Atagana HI (2004) Biodegradation of phenol, o-cresol, m-cresol and p-cresol by indigenous soil

fungi in soil contaminated with cresote. World J Microbiol Biotechnol 20:851-858

Bathe S, Schwarzenbeck N, Hauser M (2005) Plasmid-mediated bioaugmentation of activated

sludge bacteria in a sequencing batch moving bed reactor using pNB2. Lett Appl Microbiol 41:

$242-247$.

Belloso CO (2003a) In situ bioremediation of hydrocarbon-contaminated soil by autochthonous

microorganisms: a full-scale project. In: Magar VS, Kelley ME (eds.) Proceedings of the seventh international in situ and on-Site bioremediation symposium 2003, Baltelle Press,

Columbus, paper O-08.

Belloso CO (2003b) Performance improvement of an urban wastewater stabilization ponds system

by bioaugmented autochthonous bacteria: a case study. In: Magar VS, Kelley ME, (eds)

Proceedings of the seventh international in situ and on-site bioremediation symposium 2003,

Baltelle Press, Colombus, paper N-03. 
Blumenroth P, Wagner-Döbler I (1998) Survival of inoculant in polluted sediments: effect of strain origin and carbon source competition. Microb Ecol 35: 279-288.

Bouchez T, Patureau D, Dabert P, Juretschko S, Dore J, Delgenes P, Moletta R, Wagner M, (2000) Ecological study of a bioaugmentation failure. Environ Microbiol 2:179-190

Cases I, de Lorenzo V (2005) Genetically modified organisms for the environment: stories of success and failure and what we have learned from them. Int Microbiol 8: 213-222.

D’Annibale A, Rosetto F, Leonardi V, Federici F, Petruccioli M (2006) Role of autochthonous filamentous fungi in bioremediation of a soil historically contaminated with aromatic hydrocarbons. Appl Environ Microbiol 72:28-36

Dott W, Feuduejer D, Kampfer, Scgkeubunger H, Strechel (1989) Comparison of autochthonous bacteria to their effectiveness in fuel oil degradation. J Ind Microbiol 4:365-374.

Fantroussi SE, Agathos SN (2005) Is bioaugmentation a feasible strategy for pollutant removal and site remediation? Curr Opin Microbiol 8:268-275

Garon D, Sage L, Seigle-Murandi F (2004) Effects of fungal bioaugmentation and cyclodextrin amendment on fluorine degradation in soil slurry. Biodegradation 15:1-8

Gentry TJ, Josephson KL, Pepper IL (2004a) Functional establishment of introduced chlorobenzoate degraders following bioaugmentation with newly activated soil. Biodegradation 15:67-75

Gentry TJ, Rensing C, Pepper IL (2004b) New approaches for bioaugmentation as a remediation 
technology. Crit Rev Environ Sci Tech 34: 447-494.

Grosser RJ, Warshawsky D, Vestal J.R (1991) Indigenous and enhanced mineralization of pyrene, benzo[a]pyrene, and Carbazole in soils. Appl Environ Microbiol 57:3462-3469

Gurijala KR, Alexander M (1990) Explanation for the decline of bacteria introduced into lake water.

Microb Ecol 20:231-244

Hara A, Syutsubo K, Harayama S (2003) Alcanivorax which prevails in oil-contaminated seawater exhibits broad substrate specificity for alkane degradation. Environ Microbiol 5: 746-753.

Hosokawa R, Nagai M, Kondo H, Teragaki J, Okuyama H (2009) Application of autochthonous bioaugmentation in cold regions of Japan. In: Columbus F (ed) Contaminated Soils:

Environmental Impact, Disposal and Treatment. Nova Science Publishers, Inc., Hauppauge, New York. In press.

Kasai Y, Kishira H, Sasaki T, Syotsubo K, Watanabe K, Harayama S (2002) Predominant growth of Alcanivorax strains in oil-contaminated and nutrient-supplemented sea water. Environ Microbiol 4:141-147.

Major DW, McMaster ML, Cox EE, Edwards EA, Dworatzek SM, Hendrickson ER, Starr MG,

Payne JA, Buonamici LW (2002) Field demonstration of successful bioaugmentation to achieve dechlorination of tetrachloroethene to ethane. Environ Sci Technol 36:5106-5116

McKew BA, Coulon F, Yakimov MM, Denaro R, Genovese M, Smith CJ, Osbom AM, Timmis KN, 
McGenity TJ (2007) Efficacy of intervention strategies for bioremediation of crude oil in marine systems and effects on indigenous hydrocarbonoclastic bacteria. Environ Microbiol 9:1562-1571

Møller J, Gaarn H, Steckel T, Wedebye B, Westermann P (1995) Inhibitory effects on degradation of diesel oil in soil-microcosms by a commerecial bioaugmentation product. Bull Environ Contam Toxicol 54:913-918

Murakami T (2002) Sakhalin offshore oil and gas development (original title in Japanese). In:

Murakami T (ed) Sakhalin offshore oil and gas development and environmental protection, Hokkaido University Press, Sapporo, pp.3-40 (in Japanese)

Nagai M (2009) Study on autochthonous bioaugmentation tests predicting the contamination of Hokkaido coasts by crude oil (in Japanese with English Abstract). Master's thesis, Graduate School of Environmental Science, Hokkaido University, Japan.

Nancharaiah YV, Joshi HM, Hausner M, Venugopalam VP (2008) Bioaugmentation of aerobic microbial granules with Pseudomonas putida carrying TOL plasmid. Chemosphere 71:30-35

Oshima KI, Wakatsuchi M, Fukamachi Y, Mizuta G (2002) Near-surface circulation and tidal currents of the Okhotsk Sea observed with satellite-tracked drifters. J Geophys Res. 107(C11), 3195. Doi: 10.1029/2001JC001005

Otte MP, Gagnon J, Comeau Y, Matte N, Greer CW, Samson R (1994) Activation of an indigenous 
microbial consortium for bioaugmentation of pentachlorophenol/ creosote contaminated soils.

Appl Microbiol Biotechnol 40:926-932

Potin O, Rafin C, Veignie E (2004) Bioremediation of an aged polycyclic aromatic hydrocarbons (PAHs)-contaminated soil by filamentous fungi isolated from the soil. Int Biodeterior

Biodegradation 50:45-52

Rahman KSM, Rahman TJ, Kourkoutas Y, Petsas I, Marchant R, Banat IM (2003) Enhanced

bioremediation of $n$-alkane in petroleum sludge using bacterial consortium amended with

rhamnolipid and micronutrients. Bioresour Technol 90:159-168

Saeki H, Otsuka N (2002) Assumption of the trace of drifting spilled oil and the method for its

recovery (original title is in Japanese). In: Murakami T (ed) Sakhalin offshore oil and gas

development and environment protection, Hokkaido University Press, Sapporo, pp. 189-204 (in

Japanese).

Sayler GS, Ripp S (2000) Field application of genetically engineered microorganisms for

bioremediation processes. Curr Opin Biotechnol 11: 286-289

Schneiker S, Martins dos Santos VA, Bartels D, Bekel T, Brecht M, Buhrmester J, Chernikova TN,

Denaro R, Ferrer M, Gertler C, Goesman A, Golyshina OV, Kaminski F, Khachane AN, Lang S,

Linke B, McHardy AC, Meyer F, Nechitaylo T, Pühler A, Regenhardt D, Rupp O, Sabirova JS,

Selbitschka W, Yakimov MM, Timmis KN, Vorhölter FJ, Weidner S, Kaiser O, Golyshin PN 
(2006) Genome sequence of the ubiquitous hydrocarbon-degrading marine bacterium

Alcanivorax borkumensis. Nat Biotechnol 24: 997-1004.

Takeuchi M, Nanba K, Iwamoto H, Nirei H, Kusuda T, Kazaoka O, Owaki M, Furuya K (2005) In situ bioremediation of a cis-dichloroethylene-contaminated aquifer utilizing methane-rich groundwater from an uncontaminated aquifer. Water Res 39:2438-2444

Thompson IP, van der Gast CJ, Ciric L, Singer AC (2005) Bioaugmentation for bioremediation: the challenge of strain selection. Environ Microbiol 7:909-915

Torsvik V, Goksoyr J, Daae FL (1990) High diversity in DNA of soil bacteria. Appl Environ Microbiol 56: 782-787

Tsutsumi H, Kono M, Takai K, Manabe T, Haraguchi M, Yamamoto I, Oppenheimer C (2000)

Bioremediation on the shore after an oil spill from the Nakhodka in the Sea of Japan. III. Field test of a bioremediation agent with microbiological cultures for the treatment of an oil spill. Mar Pollut Bull 40: 320-324

Ueno A, Hasanuzzaman M, Yumoto I, Okuyama H (2006a) Verification of degradation of diesel oil by Pseudomonas aeruginosa strain WatG in soil microcosms. Curr Microbiol 52:182-185

Ueno A, Ito Y, Yamamoto Y, Yumoto I, Okuyama H (2006b) Bacterial community changes in diesel-oil-contaminated soil microcosms biostimulated with LURIA-BERTANI medium or bioaugmented with a petroleum-degrading bacterium, Pseudomonas aeruginosa strain WatG. J 
Basic Microbiol 46:310-317

Ueno A, Ito Y, Yumoto I, Okuyama H (2007) Isoltion and characterization of bacteria from soil contaminated with diesel oil and the possible use of these in autochthonous bioaugmentation. World J Microbiol Biotechnol 23:1739-1745

Uto S, Tamura K, Shinoda H (1995) On the measurement of Okhotsk sea ice by patrol ship Soya. In: Proceedings of NIPR Symposium on Polar Meteorology and Glaciology 9, National Institute of Polar research, Tokyo, pp.200.

van Beilen JB, Marin MM, Smits TH, Röthlisberger M, Franchini AG, Witholt B, Rojo F (2004) Characterization of two alkane hydroxylase genes from the marine hydrocarbonoclastic bacterium Alcanivorax borkumensis. Environ Microbiol 6: 264-273.

van Beilen JB, Panke S, Lucchini S, Franchini AG, Rothlisberger M, Witholt B (2001) Analysis of Pseudomonas putida alkane degradation gene clusters and flanking insertion sequences: evolution and regulation of the alk genes. Microbiology 147:1621-1630 van Homme JD, Singh A, Ward OP (2003) Recent advances in petroleum microbiology. Microbiol Mol Biol Rev 67:503-549

van Veen JA, van Overbeek LS, van Elsas JD (1997) Fate and activity of microorganisms introduced into soil. Microbiol Mol Biol Rev 67:121-135

Vecchioli GI, DelPanno MT, Painceira MT (1990) Use of selected autochthonous soil bacteria to 
enhance degradation of hydrocarbons in soil. Environ Pollut 67:249-25

Vogel TM (1996) Bioaugmentation as a soil bioremediation approach. Curr Opin Biotechnol $7: 311-316$

Vogel TM, Walter MV (2001) Bioaugmentation. In: Hurst CJ, Crawford RL, Garland JL, Lipson DA, Mills AL (ed) Manual of Environmental Microbiology, American Society for Microbiology Press, Washington D.C., pp. 952-959.

Watanabe K, Teramoto M, Harayama S (2002) Stable augmentation of activated sludge with foreign catabolic genes harboured by an indigenous dominant bacterium. Environ Microbiol 4:577-583

Weber WJ Jr, Corseuil HX (1994) Inoculation of contaminated subsurface soils with enriched indigenous microbes to enhance bioremediation rates. Water Res 28:1407-1414

Wongsa P, Tanaka M, Ueno A, Hasanuzzaman M, Yumoto I, Okuyama H (2004) Isolation and characterization of novel strains of Pseudomonas aeruginosa and Serratia marcescens possessing high efficiency to degrade gasoline, kerosene, diesel oil and lubricating oil. Curr Microbiol 49:415-422

Yakimov MM, Golyshin PN, Lang S, Moore ER, Abraham WR, Lunsdorf H, Timmis KN (1998) Alcanivorax borkumensis gen. nov., sp. nov., a new hydrocarbon-degrading and surfactant-producing marine bacterium. Int J Syst Bacteriol 48: 339-348. 


\section{Figure legend}

Fig. 1 Schematic presentation of the location of Hokkaido and Sakhalin Islands. The

pipeline from the Sakhalin oil fields to a port facing Hokkaido and the navigation route of tankers passing through the Soya Strait (brown line) are included. The flow of the East Sakhalin Current is shown by the arrow. The Hokkaido coastlines that are at risk of oil contamination from the Sakhalin oil fields are shown by the solid black line. Points A, B, and C indicate the seashores of Shari Town $\left(45^{\circ} 56^{\prime} \mathrm{N}, 144^{\circ} 43^{\prime} \mathrm{E}\right)$, Abashiri City $\left(44^{\circ} 02^{\prime} \mathrm{N}, 144^{\circ} 15^{\prime} \mathrm{E}\right)$, and Ishikari City $\left(44^{\circ} 55^{\prime} \mathrm{N}, 144^{\circ} 93^{\prime} \mathrm{E}\right)$, respectively, where sea sand was sampled. 
Table 1 Various performances conducted as autochthonous bioaugmentation (ABA) of petroleum hydrocarbons in soils and in ground waters

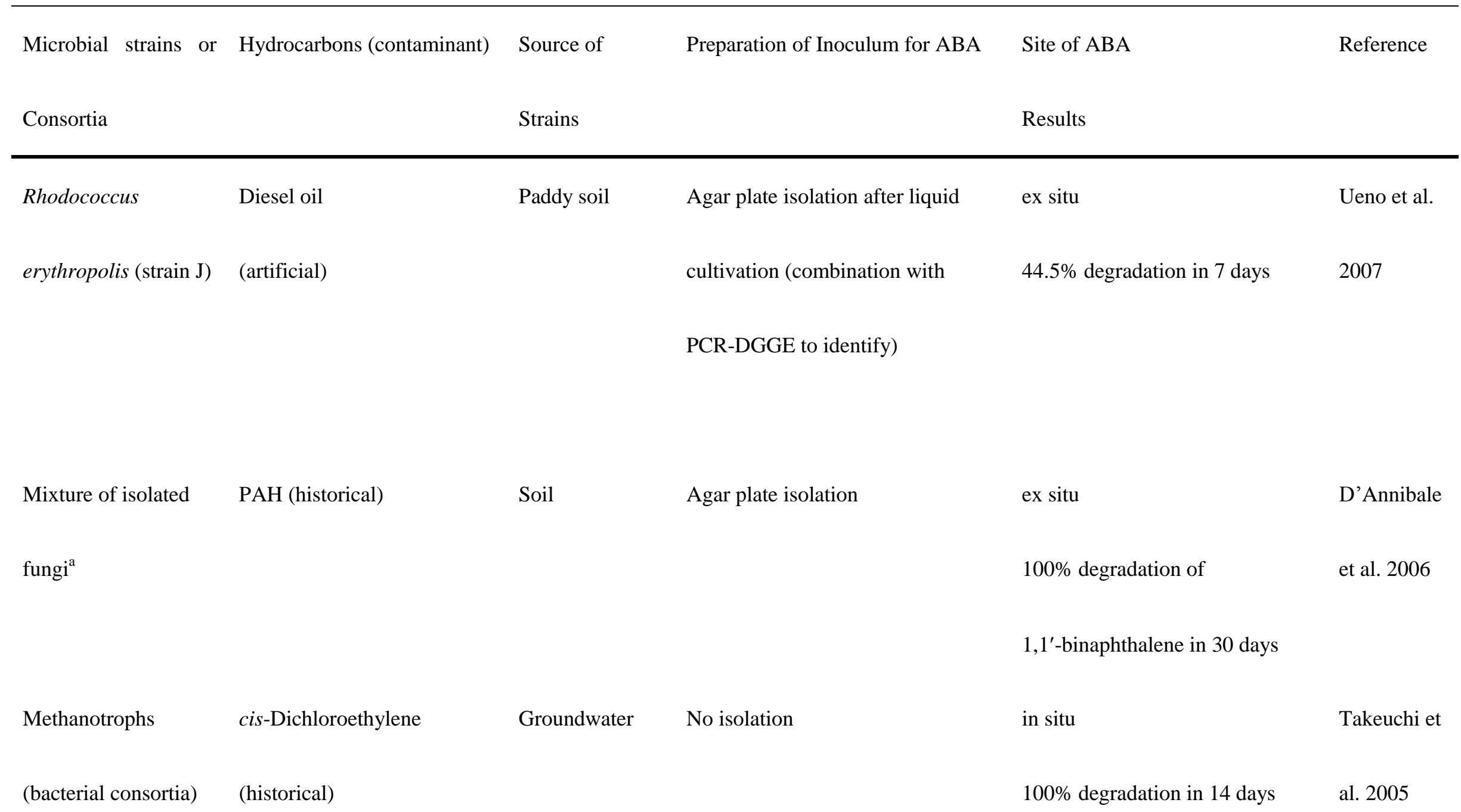




\begin{tabular}{|c|c|c|c|c|c|}
\hline Mixture of isolated & Cresol & Soil & Agar plate isolation after liquid & ex situ & Atagana \\
\hline fungi $^{\text {b }}$ & (historical) & & cultivation & $84-100 \%$ degradation in 70 days & 2004 \\
\hline Mixture of isolated & PAH & Soil & Agar plate isolation with & ex situ & Potin et al. \\
\hline \multirow[t]{2}{*}{ fungi $^{\mathrm{c}}$} & (historical) & & supernatant from mixture of dried & $26.5-27.5 \%$ degradation in 30 & 2004 \\
\hline & & & soil and agar in deionized water & days & \\
\hline Mixture of isolated & Diesel oil, PCP, creosote, & Soil (historical) & Agar plate isolation directly from & in situ & Belloso \\
\hline \multirow[t]{2}{*}{ bacteria $^{\mathrm{d}}$} & oily sludge (historical) & & soil & $74-99 \%$ degradation in 10 & $2003 a$ \\
\hline & & & & months & \\
\hline \multirow[t]{2}{*}{ Consortium $^{\mathrm{e}}$} & PCP, PAHs & Silty sand soils & Soil slurry was directly added to & ex situ & Otte et al. \\
\hline & (historical) & & bioreactor (no isolation) & $50 \%$ degradation in 1.5 days & 1994 \\
\hline
\end{tabular}




\begin{tabular}{|c|c|c|c|c|c|}
\hline Mixture of isolated & Benzene, xylene & Subsurface soils & Agar plate isolation from soil & ex situ & Weber and \\
\hline \multirow[t]{2}{*}{ bacteria $^{\mathrm{f}}$} & & (artificial) & & $50 \%$ degradation in 3 months & Corseuil \\
\hline & & & & & 1994 \\
\hline Mixture of isolated & Pyrene, carbozole, & Soil & Agar plate isolation after liquid & ex situ & Grosser et \\
\hline bacteria $^{\mathrm{g}}$ & benzo[a]pyrene (historical) & & cultivation & $55 \%$ degradation in 2 days & al. 1991 \\
\hline Mixture of isolated & Aromatic hydrocarbon & Clay loam soil & Agar plate isolation after liquid & ex situ & Vecchioli et \\
\hline bacteria $^{\mathrm{h}}$ & mixture (artificial) & & cultivation & $65 \%$ degradation in 30 days & al. 1990 \\
\hline
\end{tabular}

${ }^{a}$ Allescheriella sp. strain DABAC 1, Stachybotrys sp. strain DABAC 3, and Phelebia sp. strain DABAC 9 are contained.

${ }^{\mathrm{b}}$ Aspergillus sp., Cladosporium sp,. Fusarium sp., Monicillum sp., Penicilliumsp. and Phanerochaete are contained.

${ }^{\mathrm{c}}$ Coniothyrium sp. and Fusarium sp. are contained.

${ }^{\mathrm{d}}$ Pseudomonas cepecia, Pseudomonas stanieri, Pseudomonas fluorescens, Pseudomonas putida, Pseudomonas mendocina, Zoogloea ramigera, Moraxella lacunata,

Acinetobacter calcoaceticus, and Bacillus subtilis are contained. 
e Only Pseudomonas luteola was identified.

${ }^{\mathrm{f}}$ Xanthomonas sp. and Arthrobacter sp. are contained.

${ }^{\mathrm{g}}$ Mycobacterium sp. and Xanthomonas ampelia are contained.

${ }^{\mathrm{h}}$ Pseudomonas sp. and Alcaligenes sp. are contained. 


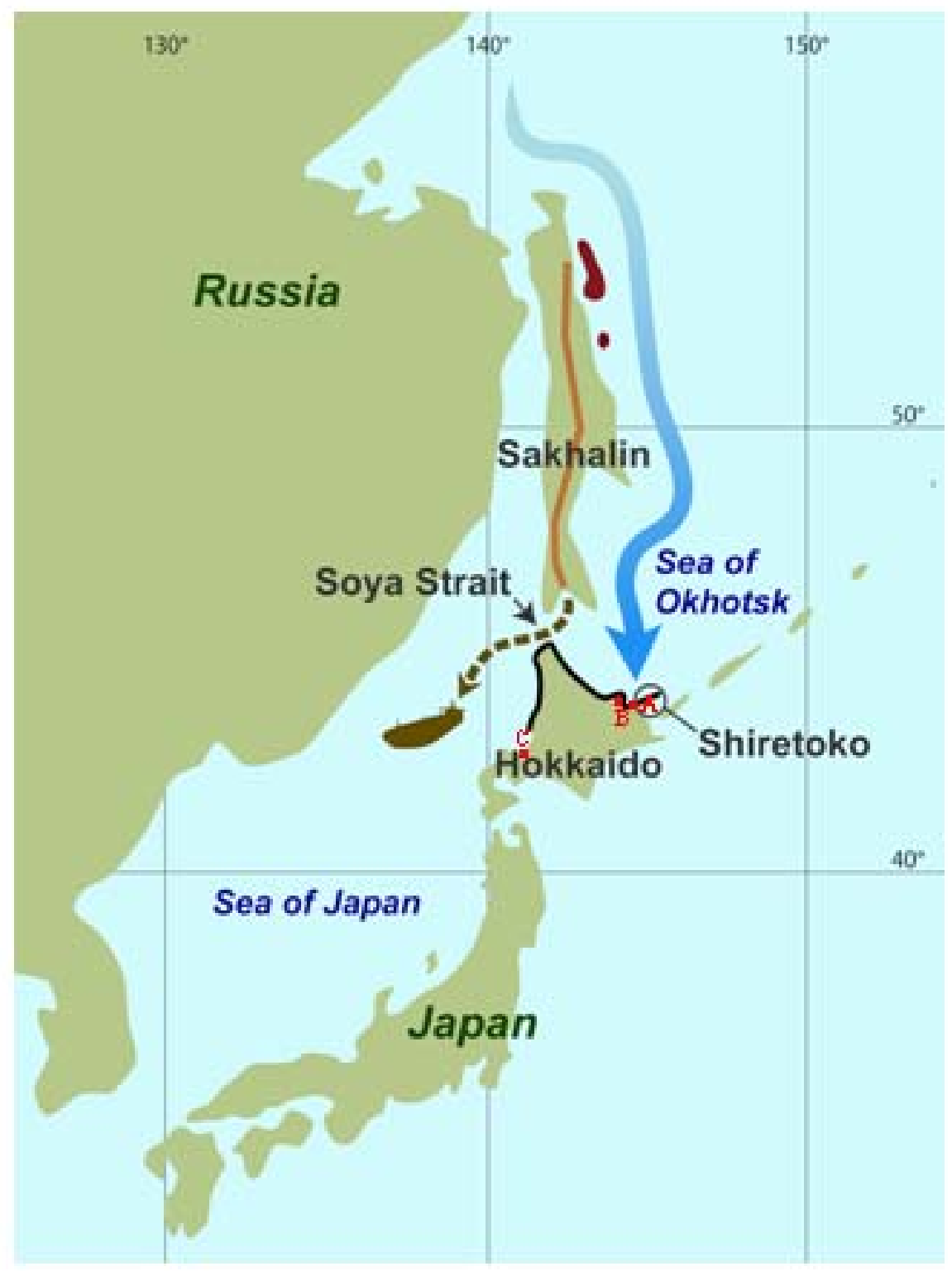

